\title{
Genealogía y poder
}

\section{Danuta Teresa Mozejko de Costa y Ricardo Lionel Costa}

\author{
Universidad Nacional de Córdoba
}

\section{INTRODUCCION}

La eficacia en el proceso de imposición de representaciones depende, en buena medida, del recurso a significaciones ya consensuadas en la sociedad donde circulan los discursos. Los enunciadores producen variaciones a partir de modos de representación compartidos, de modo tal que los efectos específicos de sentido resulten más aceptables.

La propuesta de Mitre, en la Historia de San Martín y de la emancipación sudamerican $^{l}$, de un modelo de identidad nacional, se organiza alrededor de dos modos de representación asociados: lo orgánico y la familia. Si "guerras de la independencia", "revolución", "emancipación", son nociones que involucran rupturas violentas con los agentes de dominación, el recurso a las metáforas mencionadas pone en juego significaciones que complejizan la lectura de los procesos revolucionarios en tanto simples cortes con un pasado inmediato.

La independencia es presentada por Mitre como una serie de acciones que tienen como objetivo la instauración de un orden que se opone al caos de algunos aspectos de la Colonia, y que se legitiman porque implican la posibilidad de retorno a un orden primero, natural y, por consiguiente, a un estado de armonía que se asocia con una suerte de paraíso perdido, pero recuperable. Lo orgánico, en tanto conjunto de seres vivos en el que cada parte contribuye al bienestar del todo, y la familia, como conjunto de seres humanos, entre los cuales se establecen relaciones de interdependencia armónica, se convierten en modos de representación consensuados: ambos presuponen posiciones y relaciones inscriptas en el orden de lo natural, de una consanguinidad que fija roles y que, trasladada al campo de lo humano, permite configurar, por una

${ }^{1}$ Mitre, Bartolomé. Historia de San Martín y de la emancipación sudamericana. Buenos Aires, Peuser, 1950 ( $2^{\text {a }}$ edición), 1.247 pp. Los números entre paréntesis corresponden a las páginas de esta edición. 
parte, sujetos pasionales (madre, padre, hermanos) cuyas conductas se rigen por amores y odios, adhesiones y rupturas, que matizan sus vínculos, y por otra, sujetos sometidos a las normas propias de su rol, cuyo cumplimiento es requisito no sólo para asegurar el orden social, sino también el natural. Junto con estos aspectos fácilmente aceptables por los enunciatarios de la obra de Mitre, se juegan algunos matices que nos parece útil destacar. Sin embargo, antes de entrar en ellos, creemos necesario poner de relieve ciertos elementos que ayudan a situar la obra en el espacio donde el agente social lleva a cabo el trabajo de producción-reproducción de significaciones.

\section{UNA AMENAZA}

Entre 1869 y 1895, la población de Argentina pasó de 1.737.076 a 3.954.911 habitantes. En este crecimiento jugó un papel fundamental la inmigración que, además, alcanzó sus niveles mayores en la década del $80^{2}$. El flujo migratorio tuvo aristas diferentes, y entre ellas no podría ignorarse su carácter de "amenaza". En lo económico, por ejemplo, la demanda de tierras en la pampa húmeda -recurso estratégico en torno al cual giraba fundamentalmente la producción y acumulación de riqueza y, como consecuencia, la acumulación de poder social y político- significaba un riesgo para quienes tenían la propiedad y control de las mismas.

La importancia numérica de los inmigrantes, ligada a la concentración en el tiempo y al hecho de que el contingente mayoritario era de procedencia noespañola, predominantemente italiana, constituía también una amenaza en lo cultural, en la diversidad de sus componentes como: lengua, forma de vida, ideas... ${ }^{3}$. La búsqueda de elementos que contribuyan a definir una identidad nacional puede entenderse como una acción de defensa ante la invasión de "lo ajeno", "lo extraño", que es disperso (viene de varios países) y corre el riesgo de "diluir" lo propio. Pero si, además de esto, consideramos que los agentes que principalmente intervienen en la explicitación y formulación de la identidad nacional son integrantes de la "minoría culta", la " élite ilustrada" ${ }^{4}$ es decir:

${ }^{2}$ Dentro de la década del 80, incluso, los años de mayor afluencia fueron 1887, ' 88 y 89. Sobre este aspecto, y los cambios operados en la estructura social, ver: Di Tella, Torcuato y otros, Argentina, sociedad de masas, Bs. As., Eudeba, 1965. Gallo, Ezequiel y Cortés Conde, Roberto, Argentina. La república conservadora, Bs. As., Paidós, 1995.

${ }^{3}$ Se lo verá claramente en algunos ámbitos, como el de las relaciones laborales, con la introducción de ideas anárquicas.

${ }^{4}$ Ver al respecto: Romero, José Luis, Las ideas politicas en Argentina, Bs. As., Fondo de Cultura Económica, 1975. Y: Las ideologías de la cultura nacional y otros ensayos, Bs. As., 
quienes ejercen control y administran representaciones acerca del país, su proyecto, su futuro, e incluso reclamarían el papel de orientadores de la clase social y económicamente dominante, la amenaza de la inmigración a "la identidad nacional" puede entenderse como amenaza a la élite ilustrada, y la defensa de "lo propio" contra "lo extraño", como defensa de la posición de control cultural ocupado por esta minoría culta.

El recurso a los orígenes como manera de "redescubrir lo propio que identifica y diferencia", es también empleado por Mitre. Pero no encuentra tales orígenes en los indígenas, a quienes reduce a la condición de "materia inerte" Los indígenas y sus culturas no serían aptos para fundar ni el gobierno de los criollos ni las ideas y valores dominantes en la época. Estos orígenes son ubicados en España para la cultura, y en el carácter de "nativos, hijos de conquistadores" para la clase dirigente. Todo lleva a pensar que la búsqueda de la identidad nacional, como si fuese un origen dado, por lo mismo natural y universal para todos los habitantes del país, constituiría más bien la formulación (e imposición) de un principio de visión y divisiones ${ }^{6}$, que permite excluir del derecho al poder tanto a los indígenas (materia inerte), como a los españoles (no adaptados al medio), y ahora a los inmigrantes. En otras palabras, se trataría de construir e imponer la idea acerca de la legitimidad del poder y predominio de los criollos, ocultando el carácter arbitrario de la dominación, en el imperativo de la naturaleza.

\section{LA FAMILIA}

La familia, como modelo de la nación, constituye una de las figuras más insistentemente utilizadas en la segunda mitad del siglo XIX, para dar cuenta de un modo de relación entre los ciudadanos de los países recientemente independizados que han de configurar una identidad, un modo de ser que, a manera de rasgo permanente, deberá constituir la definición de lo que "somos" y la diferencia con aquello que "no somos". En la obra de Mitre, dos son las familias que establecen lazos de consanguinidad:

Centro Editor de América Latina, 1982. También: Halperín Donghi, Tulio, Proyecto y construcción de una nación (1846-1880). Bs. As., Ariel Editora, 1995.

${ }^{5}$ Este aspecto se encuentra más desarrollado en: Mozejko, D.T., "Las definiciones de lo nacional como modelos de inclusión/exclusión: la figura heroica de San Martín”. En: Actas de las Terceras Jornadas Nacionales de Literatura Comparada, Córdoba, 1998, pp. 889-897.

${ }^{6}$ Sobre la constitución e imposición de principios de visión y división que pertenecen a posiciones específicas, como "universales", ver: Bourdieu, Pierre, Méditations Pascaliennes, París, Seuil, 1997. 


\section{- La familia particular}

San Martín es hijo de español y de una sobrina de conquistadores, y su origen étnico es claramente criollo, según la definición del texto de Mitre: descendiente directo de español, de sangre pura, adaptado al medio (38). En la medida en que es criollo, representa al actor al que corresponde el ejercicio legítimo del poder a la vez que la subordinación o eliminación de las otras razas, para configurar un grupo humano único que construya un futuro de progreso para la humanidad toda:

Desmintiendo los siniestros presagios que la condenaban a la absorción por las razas inferiores que formaban parte de su masa social, la raza criolla, enérgica, elástica, asimilable y asimiladora, las ha refundido en sí, emancipándolas y dignificándolas, y cuando ha sido necesario, suprimiéndolas, y así ha hecho prevalecer el dominio del tipo superior con el auxilio de todas las razas superiores del mundo, aclimatadas en su suelo hospitalario, y de este modo el gobierno de la sociedad le pertenece exclusivamente (58-59).

\section{- La familia como entidad colectiva}

San Martín, en cuanto personaje individual, renuncia rápidamente a su familia inmediata para inscribirse en el ámbito de lo colectivo. Lo privado cede lugar a lo público, la familia particular a la familia nacional, la patria. Hasta el lugar de nacimiento desaparece como espacio de lo privado, para incorporarse al espacio continental; la madre, doña Gregoria, renuncia al afecto de su hijo que lucha por la madre patria; la esposa se ve abandonada porque el caballero sirve a las nuevas naciones; incluso los soldados pierden sus nombres -su identidad individual- para asumir un nombre de guerra que los transforma en actores ubicados en el espacio público. Las acciones de los sujetos particulares se inscriben en el ámbito del deber ser donde los afectos personales son sustituidos por la adhesión al bien común.

\section{LAS NACIONES}

San Martín se convierte, entonces, en el conductor de un grupo humano que reconoce una genealogía y una identidad: el criollo es español y de sangre pura. La madre de familia es España, "Madre Patria", de quien se hereda un atributo: la sangre, cimiento biológico de identidad cultural, que no se ha mezclado con la de moros ni judíos y tampoco lleva restos de sangre indígena, 
ni negra, porque las otras razas han sido incorporadas a la criolla, o, cuando fue necesario, han sido suprimidas.

Lo biológico y lo cultural religioso se unen en la conformación de los límites. Pertenecer a la raza criolla vincula a los americanos con los españoles y a través de ellos, con los europeos; la frontera de lo propio coincide con la que definía la cultura peninsular:

Desde ese momento la corriente histórica que de tres siglos atrás traía el despotismo de oriente a occidente, cambia de rumbo, y la acción de los principios de la regeneración americana va de occidente a oriente y se propaga en la Europa, hasta encontrarse con su antiguo punto de conjunción en los límites del cristianismo y del islamismo (49).

También San Martín, como figura heroica que conduce al grupo, se inicia en las luchas contra los "impíos", en defensa de España.

A las raíces hispánicas de la historia privada y pública se agregan antecedentes generales de la emancipación sudamericana:

- La independencia se legitima por su inscripción en lo natural, como rasgo permanente del modo de ser americano, arraigado en lo español: el individualismo de los conquistadores, "el espíritu de individualismo que legaron a sus descendientes, en su sangre, con sus instintos de independencia" (17). La identidad se configura como herencia inscripta en la naturaleza física y, por lo mismo, legítima: "La buena y la mala semilla cultivadas en el nuevo suelo, se modificaron, se vivificaron y regeneraron, dando por producto una democracia genial, cuyo germen estaba en la naturaleza del hombre trasplantado a un nuevo medio ambiente" (17). Una vez más, la metáfora de lo orgánico, vegetal y fisiológico-humano en este caso, contribuye a legitimar los procesos de emancipación y las transformaciones posteriores. Sin embargo, opera también exclusiones que interesa destacar: los indígenas son elemento inerte (38), cosas (39), "lógicamente vencidos, ahogados para siempre en su propia sangre, porque no eran dueños de las fuerzas vivas de la sociedad, y porque no representaban la causa de la América civilizada" (39); se oponen, en consecuencia, a "los nativos, hijos de los conquistadores" (39). Si "nativo" significa: "Perteneciente al país o lugar en que uno ha nacido", "innato, propio y conforme a la naturaleza de cada cosa", la filiación española de los criollos se convierte en principio definidor de identidad natural... La adaptación al medio, como rasgo que los diferencia de los peninsulares, se traduce, en el

${ }^{7}$ Real Academia Española, Diccionario de la lengua española, Madrid, Espasa Calpe, 1970, p. 912. 
texto de Mitre, en principio de renovación dentro de la misma genealogía: la tradición española es semilla que germina en América; la independencia sudamericana es vástago del mismo tronco, el "de la raza civilizadora índicoeuropea a que está reservado el gobierno del mundo" (41). Si, además de la herencia natural, cada grupo humano se define por el reconocimiento de valores comunes, la tendencia a la armonía se asocia con un desplazamiento orientado hacia la civilización, claramente localizada en el espacio indo-europeo. Sobre estos rasgos comunes, se afirman los particularismos: descendientes de una misma familia biológica y compartiendo la misma sangre, las diferentes naciones -hijas de la misma madre- heredan, de ella, la tendencia a defender rasgos particulares.

- Desde el punto de vista político, la independencia sudamericana tiene su origen en los cabildos de la Colonia, "sombra de las antiguas comunidades libres de la madre patria" (18).

- Desde la perspectiva jurídica, las leyes americanas se originan en el sistema legal ibérico.

\section{LAS RUPTURAS}

Dentro de este marco, la separación de España se explica de varias maneras. Por una parte, la metáfora de lo orgánico-humano, asociado con la familia, inscribe el proceso de la independencia en el marco de lo natural necesario: madre e hija se separan "lógica y legalmente" (18) para conservar la vida de cada una de ellas: "El divorcio entre las colonias y la madre patria se efectuó en el momento crítico en que el abrazo que las unía las sofocaba recíprocamente, y separándose se salvaron" (44). Permítasenos observar la presencia de lexemas que retoman la metáfora de la familia: "divorcio", "madre", "abrazo", términos que refuerzan los roles familiares y los lazos afectivos involucrados, como así también los cambios operados. El divorcio se asocia con un cambio pasional en el que los lazos afectivos positivos vinculantes ("amor") son reemplazados por los negativos y escindidores ("odio", 36), y con otro posicional y de relaciones, en el que la dependencia recíproca se transforma en libertad. Dentro de la lógica del relato que se va construyendo, esta transformación tiene sus causas.

En efecto, la atribución del poder legítimo, natural, al agente colectivo "pueblo", lleva a reformular las relaciones familiares. Tanto el "pueblo" que reside en España, como el "pueblo criollo", adaptado al medio americano, tienen los mismos derechos; este principio de homología fundamental lleva a atribuirles el rol de hermanos. Si, ante la ausencia del rey, los españoles peninsulares reasumen la soberanía (47), debe reconocerse la misma facultad a los criollos 
americanos. Su negación significa un desconocimiento de derechos, que legitima el hecho de redefinir lo que se es y las relaciones que se establecen. La "madre patria", que no cumple adecuadamente con su función, se convierte en "madrastra" (40) y deja de ser patria; el servicio del héroe se desplaza hacia otra figura femenina: la "verdadera madre" (77). La oposición no se establece entre falso vs. verdadero; la figura de la madrastra española no niega el lazo biológico, sino que instaura el derecho a considerarla de otra manera, y a replantear las relaciones con ella, debido al mal ejercicio que ha hecho de sus funciones. A su vez, la "hija", siempre inscripta en el campo de lo orgánico, va creciendo como una adolescente:

[...] el organismo de la temprana edad en que el desarrollo se iniciaba y cuando el cuerpo asumía las formas externas que debía conservar[...] (19)

La separación se justifica en la medida en que la figura materna aparece degradada, y la hija representa la posibilidad de transformación, restableciendo la lógica de lo natural. La Colonia es definida como un período de inercia, un paréntesis en el proceso de crecimiento del embrión gestado por España. Ahora, "un grupo de naciones independientes, surgidas de un embrión colonial que yacía en la inercia” (11), recupera las leyes naturales olvidadas, y demanda su derecho a la igualdad fraternal. La diferencia entre los dos modos, el colonial y el independiente, radica en la instalación, por parte de la metrópolis, de relaciones feudales, jerárquicas, opuestas a las relaciones entre pares, que respetan el "individualismo" consagrado por la naturaleza. La independencia tratará de renovar el "orden social en la materia viva con arreglo a la ley de la naturaleza” (17). Se trata de legitimar tanto el origen como la ruptura, acudiendo al orden natural y sin renunciar a la genealogía, ya que "los hechos revelan la educación del vástago, y la cooperación de los antecesores muestra el germen de un nuevo orden de fenómenos" (17).

También desde el punto de vista político, la ruptura se justifica como consecuencia de una transgresión. En un período definido como enfermedad, España consagra el absolutismo y una jerarquización social que atenta contra la igualdad y la vida misma de los hijos; éstos son desheredados y desaparece el amor en la relación (22); la figura materna cede lugar al amo. Frente a esto, la emancipación resuelve un problema de subsistencia, la vida se impone gracias al impulso del individualismo, natural en los españoles adaptados al nuevo medio, que defienden la igualdad como derecho natural. El enemigo, ahora, ya no es tanto el español, sino el "realista", en tanto defensor de la monarquía

${ }^{8}$ La Real Academia Española define "realismo" como: "Doctrina u opinión favorable a la monarquía. En España se dijo con aplicación a la pura o absoluta” (op. cit., p. 1.108). 
absoluta que instala el caos social y político, la muerte, por oposición a los "patriotas", sujetos de un poder legítimo, que defienden la igualdad", respetan las normas naturales y defienden la vida.

La genealogía no se niega jamás; por el contrario, la emancipación restituye el orden natural perdido. No hay corte sino retorno al pasado legítimo, a los vínculos de consanguinidad. España cometió transgresiones en el campo jurídico y político y se alejó del orden; la independencia, al reconocer y modificar el caos, sólo recupera el cosmos inicial y asegura la vigencia de los valores tanto para las naciones americanas como para la misma España. Desde ahora, todos compartirán idéntica búsqueda de la armonía.

\section{CONCLUSION}

En este relato fundante de la identidad nacional, la genealogía aparece como instrumento para recuperar orígenes, precisar límites y legitimarlos; la ruptura con la metrópolis se funda en el crecimiento y madurez de la hija, así como en la transgresión de la "madre" que, al no cumplir con su rol, viola el orden jurídico, político y, por lo tanto, natural; sin embargo, la consanguinidad natural no se altera. La recuperación del orden se opera en una redefinición de las relaciones: una hija emancipada, es decir, liberada de la patria ${ }^{10}$ potestad, sin que cambie la sangre heredada que sigue corriendo por las venas. Sangre que resulta un fundamento biológico de identidad en un período en el que, como dice Adolfo Prieto ${ }^{11}$, "el nacionalismo antihispánico de la tradición liberal podía [...] convertirse en nacionalismo hispanizante”, la fobia hacia España se compensaba con un decreto del Poder Ejecutivo que suprimía, en el Himno Nacional, "todas las estrofas que ofendían la imagen de España y de los españoles", y se buscaba símbolos identificatorios que permitieran una diferenciación entre nosotros y los otros, esos contingentes de extranjeros que suscitaban fuertes sentimientos xenofóbicos.

${ }^{9}$ Dentro de esta misma línea de metáforas que recurren a la herencia biológica en el seno de la familia, cabe notar que las rebeliones indígenas son presentadas como "bastardas" (631).

${ }^{10}$ Nos permitimos parafrasear la definición que propone la Real Academia Española: "Emancipar": "Libertar de la patria potestad, de la tutela o de la servidumbre" (op. cit., p. 509).

${ }^{11}$ Prieto, Adolfo. El discurso criollista en la formación de la Argentina moderna. Buenos Aires, Sudamericana, 1988, p. 170. Por su parte, Esteban Buch afirma: "Esta élite [de la que forma parte Mitre] busca por entonces conciliar su espíritu liberal y cosmopolita con un impulso conservador que la lleva a cerrar filas en torno a la "tradición" [...] En efecto, la necesidad de legitimar una hegemonía que pronto sentirá amenazada por las grandes corrientes inmigratorias provoca en el seno de la oligarquía argentina una reformulación 
Pero el problema no habría sido meramente de identidad como diferencia, sino como principio que permite definir y legitimar quién tiene el derecho a "administrar lo propio" y conducir los destinos del país. ¿Cómo entender la toma de distancia en lo cultural respecto a España, proclamada ya por la Generación del 37 con la que Mitre entra en contacto y sintonía desde su juventud en Montevideo, y que continúa la élite letrada y liberal de la que forma parte -abierta al pensamiento de franceses, ingleses, norteamericanos-, con el recurso a España como madre en la que se encuentra el origen y principio de identidad, si no por la modificación de los intereses que están en juego ante el surgimiento de amenazas nuevas al poder de la élite letrada? Cabe preguntarse si lo que está en cuestión, e independientemente de la conciencia que de ello pudieran tener los agentes involucrados, es la identidad y los principios, o el poder y los intereses.

La puesta en relación de algunos elementos que caracterizan el espacio social y la posición ${ }^{12}$ desde la que Mitre produce su obra, con las representaciones allí elaboradas, permite formular la hipótesis según la cual el principio de selección de lo que se incluye y/o excluye a nivel de representaciones, así como el manejo que se hace de significaciones, analogías, oposiciones..., se constituye en la articulación de dos órdenes de condicionamientos: la posición relativa del agente social en el sistema de relaciones y los intereses ligados a la misma, por una parte; $y$, por otra, el hecho de que no cualquier estrategia es apta para asegurar la eficacia en el proceso de producción e imposición de representaciones.

\section{BIBLIOGRAFIA CITADA}

Bourdieu, Pierre, Méditations Pascaliennes, París, Seuil, 1997.

, Las reglas del arte, Barcelona, Anagrama, 1995.

Buch, Esteban, O juremos con gloria morir. Historia de una épica de Estado. Buenos Aires, Sudamericana, 1994.

Di Tella, Torcuato y otros, Argentina, sociedad de masas, Bs. As., Eudeba, 1965. Gallo, Ezequiel y Cortés Conde, Roberto, Argentina. La república conservadora, Bs. As., Paidós, 1995.

ideológica en cuyo transcurso se verá al nacionalismo antihispánico liberal volverse nacionalismo hispanizante; habrá entonces que adaptar el himno para que armonice con el nuevo rol que se reserva a la "madre patria" en el relato mítico de los orígenes de la nación" (Cf. Buch, Esteban. O juremos con gloria morir. Historia de una épica de Estado. Buenos Aires, Sudamericana, 1994, p. 90.

${ }^{12}$ Empleamos estos términos en el sentido que les da P. Bourdieu en, por ejemplo: Las reglas del arte, Barcelona, Anagrama, 1995. 
Halperín Donghi, Tulio, Proyecto y construcción de una nación (1846-1880). Bs. As., Ariel Editora, 1995.

Mitre, Bartolomé, Historia de San Martín y de la emancipación sudamericana. Buenos Aires, Peuser, 1950 (2a edición).

Mozejko, Danuta T., "Las definiciones de lo nacional como modelos de inclusión/ exclusión: la figura heroica de San Martín”. En: Actas de las Terceras Jornadas Nacionales de Literatura Comparada, Córdoba, 1998, pp. 889-897.

Prieto, Adolfo, El discurso criollista en la formación de la Argentina moderna. Buenos Aires, Sudamericana, 1988.

Real Academia Española, Diccionario de la lengua española, Madrid, Espasa Calpe, 1970.

Romero, José Luis, Las ideas políticas en Argentina, Bs. As., Fondo de Cultura Económica, 1975.

Editor de América Latina, 1982.

Based on the hypotheses that the characteristics of the discourse and the competence of the social agents that produce it maintain a relationship that we call of coherency, we analyze the metaphor of the family used by Bartolomé Mitre in the Historia de San Martín y de la emancipación sudamericana to represent the nation. In that respect, we sustain that this figure allows for a naturalization of the bonds among the citizens, as well as those with their homeland and with Spain, that makes it particularly acceptable and, for the same reasons, facilitating the imposition of a national model that the cultured elite constructs. The trope bocomes a way to set limits that define inclusions and exclusions: the family is made up of the sons of spaniards adapted to the environment, thus eliminating the indigenous as "inert matter", the spaniards for not being adapted, and the immigrants that constituted, at the time the text was written, a threat to the cultured elite that exerted the control and administrated the representations of the nation. 